\title{
Antennas of RFID Tags
}

\author{
Ahmed M. A. Salama \\ College of Electronics Engineering \\ University of Mosul \\ Iraq
}

\section{Introduction}

Radio Frequency Identification (RFID) is a rapidly developing technology which uses RF signals for automatic identification of objects. RFID system generally consists of three components: 1) A small electronic data carrying device called a transponder or tag that is attached to the item to be identified, 2) A reader that communicates with the tag using radio frequency signals, 3) A host data processing system that contains the information of the identified item and distributes the information between other remote data processing systems. A typical passive RFID tag consists of an antenna and RFID chip. RFID tags can be active (with battery) or passive (without battery). In particular, passive UHF (860 960) $\mathrm{MHz}$ tags represent a near optimal combination of cost and performance (Hunt et al., 2007). Generally, omni directionality for the tag antenna is preferred to ensure the identification from all directions. The structure of the tag antenna should also be low cost, small in size, have good impedance matching and insensitive to the attached objects to keep performance consistent (Curty et al., 2007).

A passive RFID system operates in the following way: RFID reader transmits a modulated RF signal to the RFID tag consisting of an antenna and an integrated circuit chip. The chip receives power from the antenna and responds by varying its input impedance and thus modulating the backscattered signal. Modulation type often used in RFID is amplitude shift keying (ASK) where the chip impedance switches between two states: one is matched to the antenna (chip collects power in that state) and another one is strongly mismatched. The most important RFID system performance characteristic is tag range - the maximum distance at which RFID reader can either read or write information to the tag. Tag range is defined with respect to a certain read/write rate (percentage of successful reads/writes) which varies with a distance and depends on RFID reader characteristics and propagation environment (Nikitin \& Rao, 2006).

In this chapter, the operation theory of the RFID system is described. The antenna in RFID system is discussed, and the designing considerations of the antennas for RFID applications are presented. Also the design, simulation and implementation of some commonly used antennas in the RFID system are presented and investigated. IE3D electromagnetic simulator based on Method of Moment (MoM) is used to design some of these antennas.

Source: Radio Frequency Identification Fundamentals and Applications, Design Methods and Solutions, Book edited by: Cristina Turcu, ISBN 978-953-7619-72-5, pp. 324, February 2010, INTECH, Croatia, downloaded from SCIYO.COM 


\section{Operation theory of RFID tags}

As known, passive RFID tags does not have its own power supply (i.e. battery less) ,so it depends on the received signal to power up the tag circuitry and resends the data to the reader. In this section, the operation of RFID tags is discussed and analyzed as well as the powers at the tag terminals and reader antenna are calculated.

\subsection{Link budget}

To calculate the power available to the reader $P_{r}$, the polarization losses will assume to be neglected and line-of-sight (LOS) communication is presented. As shown in Fig. 1, $P_{r}$ is equal to $G_{r} P^{\prime}{ }_{r}$ and can be expressed as shown in equation (1) by considering the tag antenna gain $G_{t}$ and the tag-reader path loss (Curty et al., 2007):

$$
\begin{aligned}
P_{r} & =G_{r} P_{r}^{\prime}=G_{r} P_{b}^{\prime}\left(\frac{\lambda}{4 \pi d}\right)^{2} \\
& =G_{r} G_{t} P_{b}\left(\frac{\lambda}{4 \pi d}\right)^{2}
\end{aligned}
$$

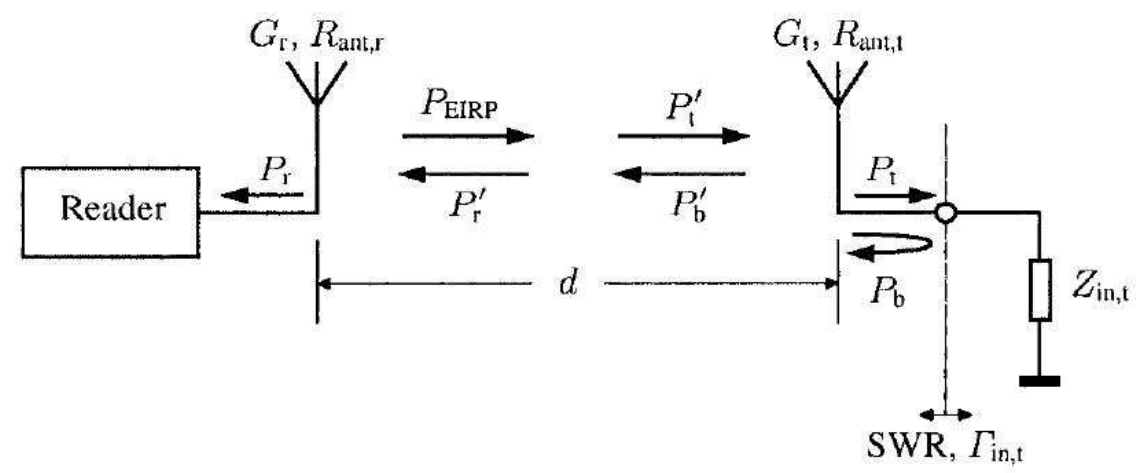

Fig. 1. Link budget calculation (Curty et al., 2007).

$P^{\prime}{ }_{b}$ can be calculated using SWR between the tag antenna and the tag input impedance:

$$
P_{b}=P_{t}\left(\frac{S W R-1}{S W R+1}\right)^{2}
$$

Or can be expressed using the reflection coefficient at the interface $\left(\Gamma_{\text {in }}\right)$ as shown below:

$$
P_{b}=P_{t}\left|\Gamma_{i n}\right|^{2}
$$

The transmitted power $\left(P_{E I R P}\right)$ is attenuated by reader-tag distance, and the available power at the tag is: 


$$
P_{t} G_{t}=P_{E I R P}\left(\frac{\lambda}{4 \pi d}\right)^{2}
$$

Substituting equations (3), (4) and (5) in equation (1) will result in the link power budget equation between reader and tag.

$$
P_{r}=G_{r} G_{t}^{2}\left(\frac{\lambda}{4 \pi d}\right)^{4}\left(\frac{S W R-1}{S W R+1}\right)^{2} P_{E I R P}
$$

Or can be expressed in term of $\left(\Gamma_{\text {in }}\right)$, so equation (2.6) will become:

$$
P_{r}=G_{r} G_{t}^{2}\left(\frac{\lambda}{4 \pi d}\right)^{4}\left|\Gamma_{i n}\right|^{2} P_{E I R P}
$$

The received power by the reader is proportional to the $(1 / d)^{4}$ of the distance and the matching between the tag antenna and tag RFID IC as well as $\left(P_{r}\right)$ is depending on the gain of the reader and tag antennas. In other words, the Read Range of RFID system is proportional to the fourth root of the reader transmission power $P_{E I R P}$.

\section{Complex conjugate concept}

For the ac circuit shown in Fig. (2) which consists of fixed voltage with peak value $V_{s}$ and an internal impedance $Z_{s}=R_{s}+j X_{s}$ and an external load $Z_{L}=R_{L}+j X_{L}$, the load will deliver $\left(1 / 2 V_{s}\right)$ when $Z_{L}=Z_{s}^{*}$ (Zhan, 2006) .

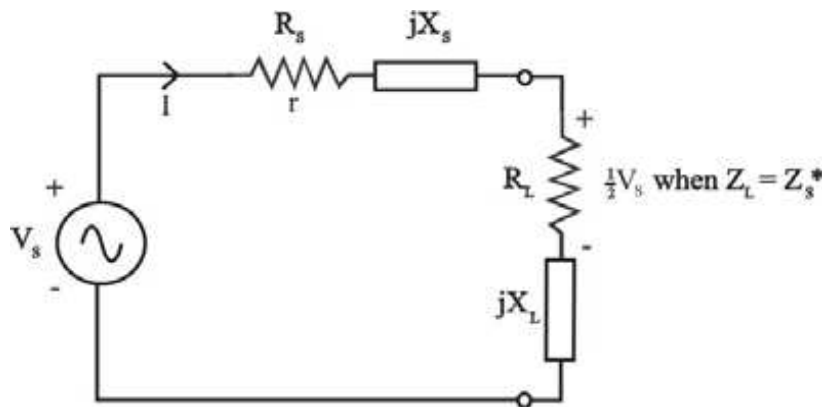

Fig. 2. Context for maximum power transfer theorem (Zhan, 2006)

The maximum power transfer theorem states that: for a linear network with fixed source impedance, the maximum power is delivered from the source to the load when the load impedance is the complex conjugate of the source impedance, that is:

$$
\mathrm{Z}_{\mathrm{L}}=\mathrm{Z}_{\mathrm{S}}^{*}
$$

Which means that $R_{L}=R_{s}$ and $j X_{L}=-j X_{s}$, and the circuit is said to be conjugately matched.

The available source power is given by:

$$
\text { available source power }=\frac{\left|V_{s}\right|^{2}}{8 R_{s}}
$$


As mentioned before, the RFID tag consists of an antenna and RFID integrated circuit (RFID IC) which can be illustrated by its equivalent circuits as shown below:

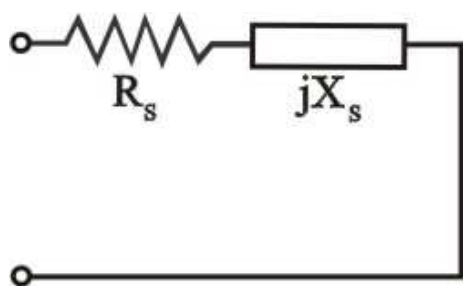

Fig. 3. The Equivalent circuit of the RFID circuit

Typically, $X_{s}$ is capacitive and it comes from the rectifier capacitor which is about (1pf) this means an impedance of $(-\mathrm{j} 200 \Omega)$ at a frequency of $915 \mathrm{MHz}$, and $\mathrm{R}_{\mathrm{s}}$ is about $(10 \Omega)$. The tag impedance will be $Z_{c}=10-200 \Omega$, this is an approximate value, but the exact chip impedance value can be obtained from chip manufacturer or can be measured by using network analyzer. The voltage reflection coefficient of a load $\mathrm{Z}_{\mathrm{L}}$ on a transmission line of impedance $Z_{\mathrm{o}}$ is defined as follow:

$$
\Gamma=\frac{Z_{L}-Z_{o}}{Z_{L}+Z_{o}}
$$

Where $Z_{L}$ is the load impedance and $Z_{o}$ is the line impedance. If the circuit is perfectly matched, maximum possible power will be transferred from the transmission line to the load. In the case of perfect matching between the antenna and the RFID IC there will be maximum power transfer. Also a perfect matching will result in zero voltage reflection coefficient.

Smith chart can be used for designing. If the RFID IC has input impedance of $(10-j 200) \Omega$, this value can be represented on smith chart as shown below:

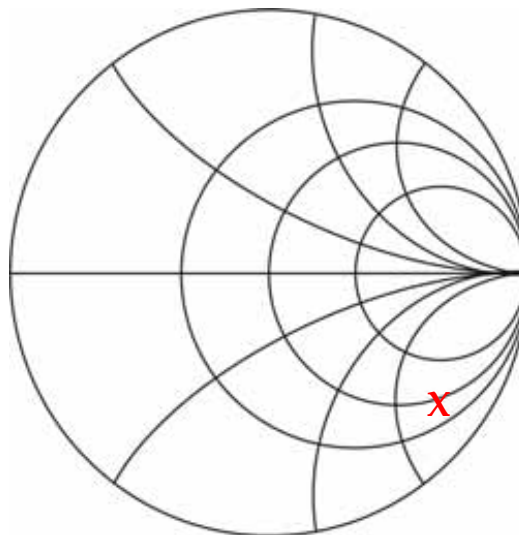

Fig. 4. Approximate position of $10 \Omega-j 200 \Omega$ in Smith Chart

The RFID IC has capacitive impedance, so an inductive antenna with impedance of $(10+$ j200) $\Omega$ (see Fig. 5) is required to obtain complex conjugate matching (perfect matching). 
If the inductance is too low, matching networks can be used or lumped elements can be added.

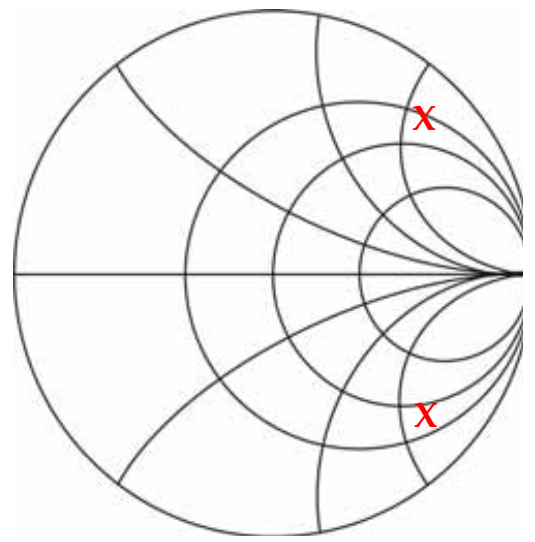

Fig. 5. Desired position of inductive antenna and capacitive chip

\section{Types of RFID tag antennas}

In this section, an overview of some antenna designs for passive UHF RFID tag is presented. These types are different from design to another depending on the application. There is no perfect antenna for all applications. It is the application that defines the antenna specifications. There is a high probability that many types of transponders will share the same IC but will connect to different antenna types. Patch antennas are well appropriate for metallic objects since it is possible to make use of their bodies as a ground plane (Curty et al., 2007). Inverted-F antennas are also mountable on such objects (Ukkonen et al., 2004). Other types of materials, e.g. (wood, cardboard, water, etc.), also allow differential antennas. These antennas offer the advantage of higher radiation resistance compared with single ended versions.

In the following sub-sections, some of these designs will be taken in details:

\subsection{Meandered antennas}

Meandered line antennas are interesting class of resonant antennas and they have been widely studied in order to reduce the physical size of the radiating elements in wire antennas like: monopole, dipole and folded dipole antennas. Increasing the total wire length in antenna of fixed axial length will lower its resonant frequency. One of the design requirements is miniaturizing the antenna, so meandering sections are added to the ordinary dipole antenna to reduce its physical size as shown below in Fig.6 (Rao et al., 2005). As the chip has a highly capacitive part in its impedance, the impedance of the designed antenna should have a highly inductive part as mentioned in the complex conjugate matching concept. To provide a better matching for the chip capacitive impedance, one meandered section was further meandered and a loading bar is added to obtain additional inductance. This antenna can be easily tuned by trimming. Lengths of meander trace and loading bar can be varied to obtain optimum reactance and resistance matching. The trimming is realized by punching holes through the antenna trace at defined locations. For 
example, trimming the meander trace by $\Delta x=5 \mathrm{~mm}$ moves the resonant frequency up by 20 $\mathrm{MHz}$ as shown in Fig. 7. The gain is not significantly affected by trimming as shown in Fig.8.

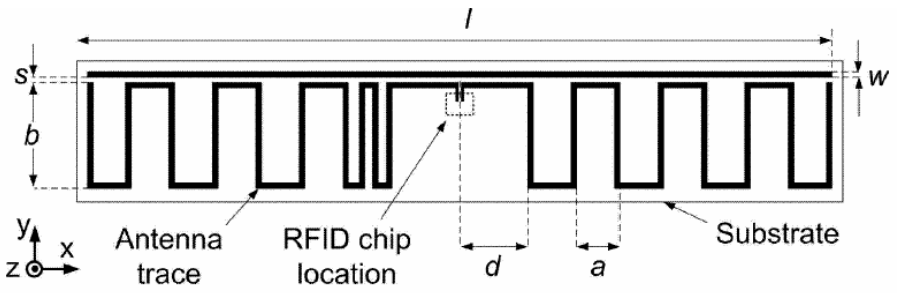

Fig. 6. Meandered line antenna

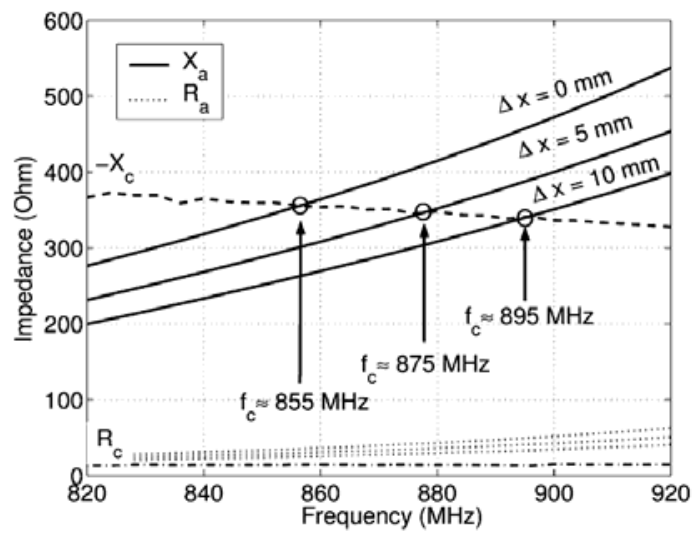

Fig. 7. Impedance of the loaded meander tag antenna $\left(R_{a}, X_{a}\right)$ as a function of meander trace length trimming $\Delta x$

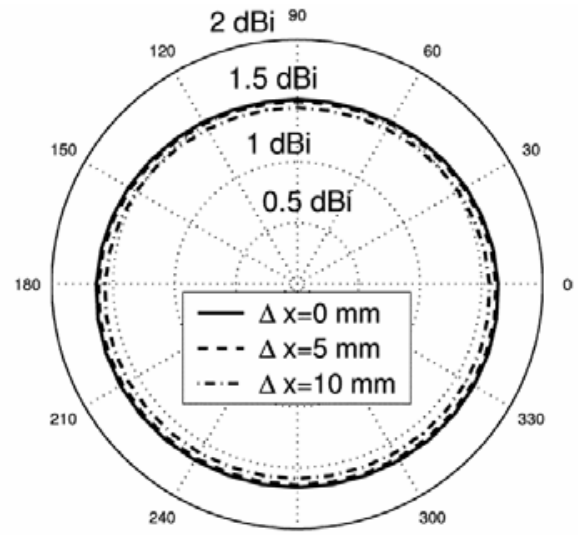

Fig. 8. Gain of the loaded meander tag antenna in yz-plane at $900 \mathrm{MHz}$ as a function of meander trace length trimming $\Delta \mathrm{x}$ 


\subsection{Text antennas}

Text can be used as a meandered line antenna (Salama \& Quboa, 2008a). Using text as an antenna element in RFID tags is given with good reason; brand names or manufacturer logos can be used to form a radiating element for the RFID tag antenna which gives an additional value to the tag itself as a hi-tech advertisement. In this section the use of text as a meandered line for dipole antennas is discussed. Size reduction is compared to the ordinary dipole antenna operating at the same frequency and printed on the same substrate.

Fig.9 shows the antenna configurations of antenna No.1 and antenna No.2 where the letters of the text "UNIVERSITY OF MOSUL" are connected together in two different ways. In antenna No.1, the text is in contact with a straight dipole structure underneath the letters, whereas in antenna No.2, the letters are joined together from top and bottom of the letters alternatively to form a meander line structure.

Fig.10 shows the simulated return loss for the antennas No.1 and No.2. As shown in Fig.10, antenna No.2 has the better return loss. The Text antenna can be implemented and fabricated using PCB technology as shown in Fig.11.
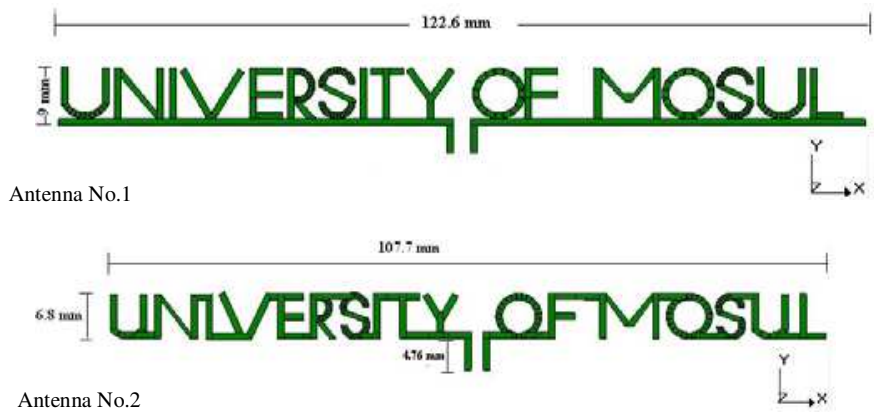

Fig. 9. Using Text as antennas for RFID tags

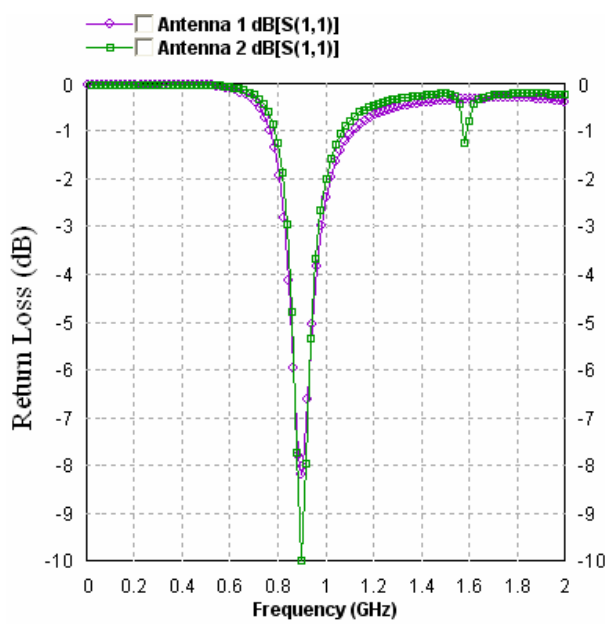

Fig. 10. The simulated return loss for the antennas No.1 and No.2. 


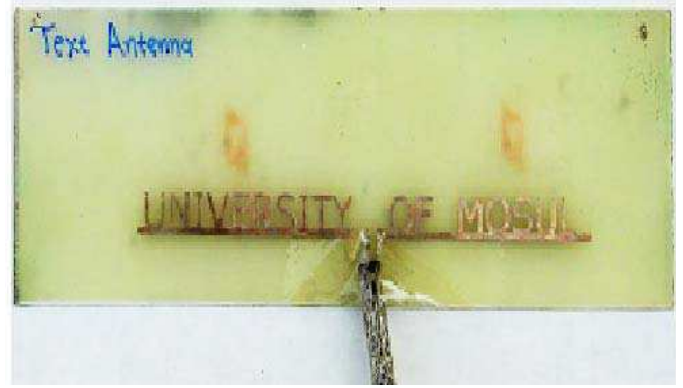

Fig. 11. Photograph of the fabricated Text Antenna.

\subsection{Fractal antennas}

The interaction of electromagnetic waves with fractal geometries has been studied. Most fractal objects have self-similar shapes, which mean that some of their parts have the same shape as the whole object but at a different scale. The construction of many ideal fractal shapes is usually carried out by applying an infinite number of times (iterations) an iterative algorithms such as Iterated Function System (IFS). IFS procedure is applied to an initial structure called initiator to generate a structure called generator which replicated many times at different scales. Fractal antennas can take on various shapes and forms. For example, quarter wavelength monopole can be transformed into shorter antenna by Koch fractal. The Minkowski island fractal is used to model a loop antenna. The Sierpinski gasket can be used as a fractal monopole (Werner \& Ganguly, 2003). When designing a small antenna, it is important to have a large effective length because the resonant frequency would be lower. The shape of the fractal antenna is formed by an iterative mathematical process. This process can be described by an Iterative Function System (IFS) algorithm, which is based upon a series of affine transformations which can be described by equation (11) (Baliarda et al., 2005):

$$
\omega=\left[\begin{array}{lllll}
r \cos \theta-r \sin \theta & r \sin \theta & r \cos \theta & e & f
\end{array}\right]
$$

Where $r$ is a scaling factor and $\theta$ is the rotation angle, $e$ and $f$ are translation involved in the transformation.

Fractal antennas provide a compact, low-cost solution for a multitude of RFID applications. Because fractal antennas are small and versatile, they are ideal for creating more compact RFID equipment - both tags and readers. The compact size ultimately leads to lower cost equipment, without compromising power or read range. In this section, some fractal antennas will be described with their simulated and measured results such as: fractal dipoles and fractal loops.

\subsubsection{Fractal dipole antennas}

A standard Koch curve (with indentation angle of $60^{\circ}$ ) will be investigated (Salama \& Quboa, 2008b), which has a scaling factor of $r=1 / 3$ and rotation angles of $\theta=0,60,-60$, and 0 . There are four basic segments that form the basis of the Koch fractal antenna, which are shown in Fig. 12. The geometric construction of the standard Koch curve is fairly simple. One starts with a straight line as an initiator as shown in Fig. 12. The initiator is partitioned 
into three equal parts, and the segment at the middle is replaced with two others of the same length to form an equilateral triangle. This is the first iterated version of the geometry and is called the generator as shown in Fig. 12.

From the IFS approach, the basis of the Koch fractal curve can be written using equation (11). The fractal shape in Fig. 12 represents the first iteration of the Koch fractal curve. From there, additional iterations of the fractal can be performed by applying the IFS approach to each segment.

It is possible to design small antenna that has the same end-to-end length than their Euclidean counterparts, but much longer. When the size of an antenna is made much smaller than the operating wavelength, it becomes highly inefficient, and its radiation resistance decreases. The challenge is to design small and efficient antennas that have a fractal shape.

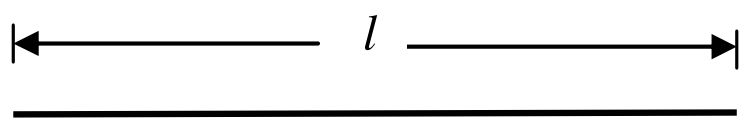

(a) Initiator

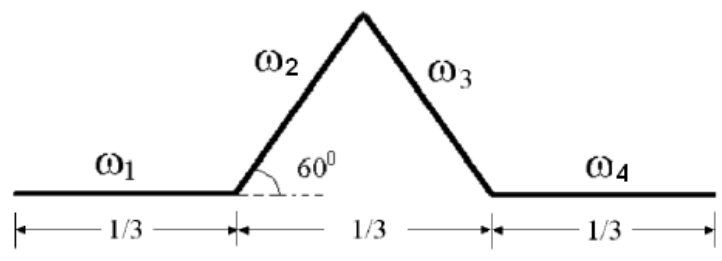

(b) Generator

Fig. 12. Initiator and Generator of the standard Koch fractal curve.

Dipole antennas with arms consisting of Koch curves of different indentation angles and fractal iterations are investigated in this section. A standard Koch fractal dipole antenna using $3^{\text {rd }}$ iteration curve with an indentation angle of $60^{\circ}$ and with the feed located at the center of the geometry is shown in Fig.13.

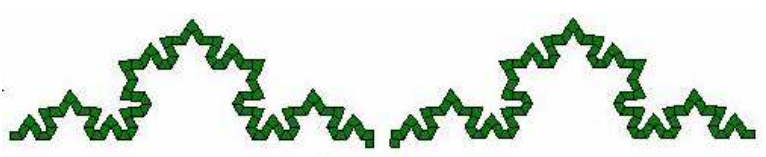

Fig. 13. Standard Koch fractal dipole antenna.

Table 1 summarizes the standard Koch fractal dipole antenna properties with different fractal iterations at reference port of impedance $50 \Omega$. These dipoles are designed at resonant frequency of $900 \mathrm{MHz}$.

The indentation angle can be used as a variable for matching the RFID antenna with specified IC impedance. Table 2 summarizes the dipole parameters with different indentation angles at $50 \Omega$ port impedance. Each dipole has an end-to-end length of $102 \mathrm{~mm}$. 


\begin{tabular}{|c|c|c|c|c|c|}
\hline $\begin{array}{c}\text { Iter. } \\
\text { No. }\end{array}$ & $\begin{array}{c}\text { Dim. } \\
(\mathbf{m m})\end{array}$ & $\begin{array}{c}\text { RL } \\
(\mathbf{d B})\end{array}$ & $\begin{array}{c}\text { Impedance } \\
(\mathbf{\Omega})\end{array}$ & $\begin{array}{c}\text { Gain } \\
\mathbf{( d B i})\end{array}$ & $\begin{array}{c}\text { Read } \\
\text { Range } \\
(\mathbf{m})\end{array}$ \\
\hline $\mathrm{K} 0$ & 127.988 & -27.24 & $54.4-\mathrm{j} 0.95$ & 1.39 & 6.22 \\
\hline $\mathrm{K} 1$ & $108.4 \times 17$ & -17.56 & $38.4+\mathrm{j} 2.5$ & 1.16 & 6 \\
\hline $\mathrm{K} 2$ & $96.82 \times 16$ & -12.5 & $32.9+\mathrm{j} 9.5$ & 0.88 & 5.72 \\
\hline $\mathrm{K} 3$ & $91.25 \times 14$ & -11.56 & $29.1-\mathrm{j} 1.4$ & 0.72 & 5.55 \\
\hline
\end{tabular}

Table 1. Effect of fractal iterations on dipole parameters.

\begin{tabular}{|c|c|c|c|c|c|}
\hline $\begin{array}{c}\text { Indent. } \\
\text { Angle } \\
\text { (Deg.) }\end{array}$ & $\begin{array}{c}f_{r} \\
(\mathbf{G H z})\end{array}$ & $\begin{array}{c}\mathbf{R L} \\
\mathbf{( d B})\end{array}$ & $\begin{array}{c}\text { Impedance } \\
(\mathbf{\Omega})\end{array}$ & $\begin{array}{c}\text { Gain } \\
(\mathbf{d B i})\end{array}$ & $\begin{array}{c}\text { Read } \\
\text { Range } \\
(\mathbf{m})\end{array}$ \\
\hline 20 & 1.86 & -20 & $60.4-\mathrm{j} 2.6$ & 1.25 & 6.08 \\
\hline 30 & 1.02 & -22.53 & $46.5-\mathrm{j} 0.6$ & 1.18 & 6.05 \\
\hline 40 & 0.96 & -19.87 & $41-\mathrm{j} 0.7$ & 1.126 & 6 \\
\hline 50 & 0.876 & -14.37 & $35.68+\mathrm{j} 7$ & 0.992 & 5.83 \\
\hline 60 & 0.806 & -12.2 & $30.36+\mathrm{j} 0.5$ & 0.732 & 5.6 \\
\hline 70 & 0.727 & -8.99 & $23.83-\mathrm{j} 1.8$ & 0.16 & 5.05 \\
\hline
\end{tabular}

Table 2. Effect of indentation angle on Koch fractal dipole parameters.

Another indentation angle search between $20^{\circ}$ and $30^{\circ}$ is carried out for better matching. The results showed that $3^{\text {rd }}$ iteration Koch fractal dipole antenna with $27.5^{\circ}$ indentation angle has almost $50 \Omega$ impedance. This modified Koch fractal dipole antenna is shown in Fig.14. Table 3 compares the modified Koch fractal dipole (K3-27.5') with the standard Koch fractal dipole $\left(\mathrm{K} 3-60^{\circ}\right)$ both have resonant frequency of $900 \mathrm{MHz}$ at reference port $50 \Omega$.

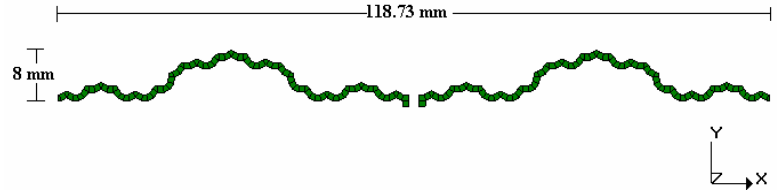

Fig 14. The modified Koch fractal dipole antenna (K3-27.5º.

\begin{tabular}{|c|c|c|c|c|c|}
\hline $\begin{array}{c}\text { Antenna } \\
\text { type }\end{array}$ & $\begin{array}{c}\text { Dim. } \\
(\mathbf{m m})\end{array}$ & $\begin{array}{c}\mathbf{R L} \\
\mathbf{( d B})\end{array}$ & $\begin{array}{c}\text { Impedance } \\
\mathbf{( \Omega )}\end{array}$ & $\begin{array}{c}\text { Gain } \\
(\mathbf{d B i})\end{array}$ & $\begin{array}{c}\text { Read } \\
\text { Range } \\
(\mathbf{m})\end{array}$ \\
\hline $\mathrm{K} 3-60^{\circ}$ & $91.2 \times 14$ & -11.56 & $29.14-\mathrm{j} 1.4$ & 0.72 & 5.55 \\
\hline K3-27.5० & $118.7 \times 8$ & -33.6 & $48+\mathrm{j} 0.48$ & 1.28 & 6.14 \\
\hline
\end{tabular}

Table 3. Comparison of $\left(\mathrm{K} 3-27.5^{\circ}\right)$ parameters with $\left(\mathrm{K} 3-60^{\circ}\right)$ at reference port $50 \Omega$. 
From Table 3, it is clear that the modified Koch dipole (K3-27.5') has better characteristics than the standard Koch fractal dipole (K3-60\%) and has longer read range.

Another fractal dipole will be investigated here which is the proposed fractal dipole (Salama \& Quboa, 2008b). This fractal shape is shown in Fig.15 which consists of five segments compared with standard Koch curve (60 indentation angle) which consists of four segments, but both have the same effective length.

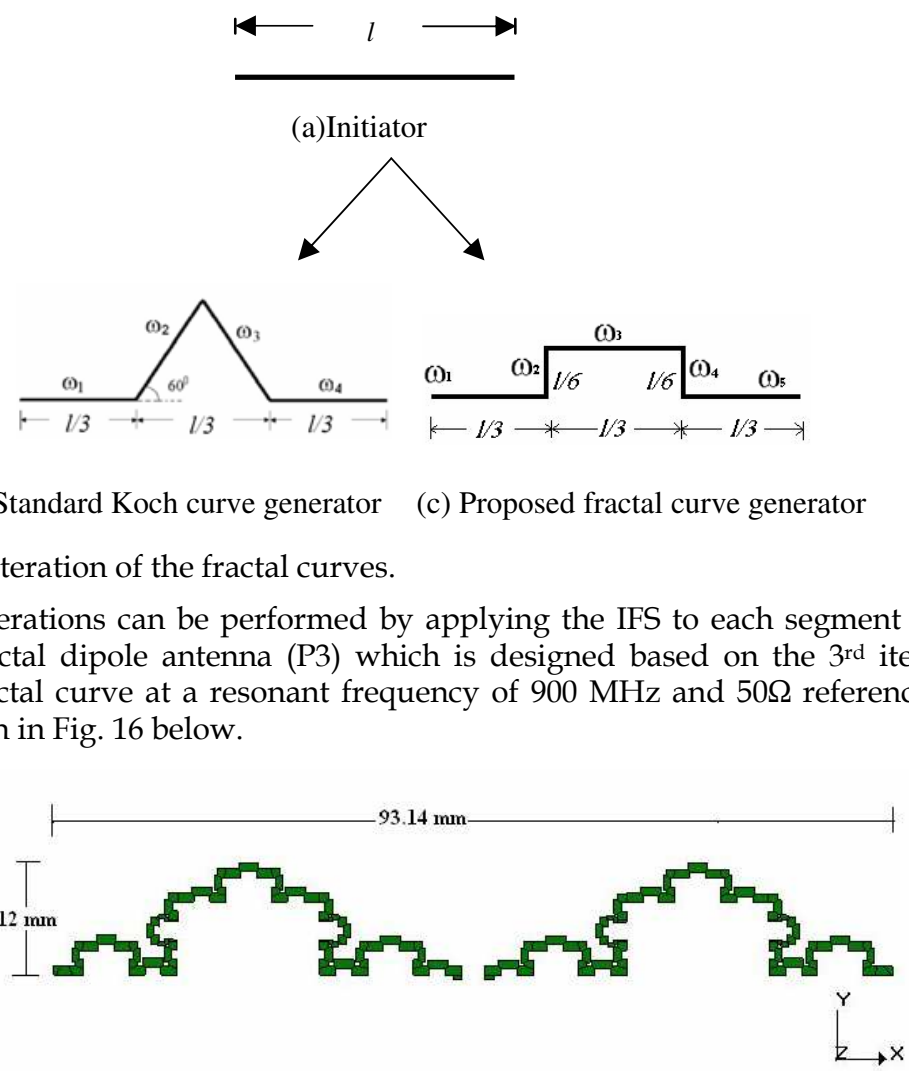

Fig. 16. The proposed fractal dipole antenna (P3) (Salama \& Quboa, 2008b).

Table 4 summarizes the simulated results of P3 as well as those of the standard Koch fractal dipole antenna $\left(\mathrm{K} 3-60^{\circ}\right)$.

\begin{tabular}{|c|c|c|c|c|c|}
\hline $\begin{array}{c}\text { Antenna } \\
\text { type }\end{array}$ & $\begin{array}{c}\text { Dim. } \\
(\mathbf{m m})\end{array}$ & $\begin{array}{c}\mathbf{R L} \\
\mathbf{( d B})\end{array}$ & $\begin{array}{c}\text { impedance } \\
\mathbf{( \Omega )}\end{array}$ & $\begin{array}{c}\text { Gain } \\
\mathbf{( d B i})\end{array}$ & $\begin{array}{c}\text { Read } \\
\text { Range } \\
(\mathbf{m})\end{array}$ \\
\hline K3-60。 & $91.2 \times 14$ & -11.56 & $29.14-\mathrm{j} 1.4$ & 0.72 & 5.55 \\
\hline P3 & $93.1 \times 12$ & -14.07 & $33.7+\mathrm{j} 3$ & 0.57 & 5.55 \\
\hline
\end{tabular}

Table 4. The simulated results of P3 compared with (K3-60) 
These fractal dipole antennas can be fabricated by using PCB technology as shown in Fig.17 and Fig.18 respectively. A suitable $50 \Omega$ coaxial cable and connector should be connected to that fabricated antennas. In order to obtain balanced currents, Bazooka balun may used. The performance of the fabricated antennas is verified by measurements. Radiation pattern and gain can be measured in anechoic chamber to obtain accurate results. The measured radiation pattern for (K3-27.5 ) and (P3) fractal dipole antennas also shown in Fig.19 which is in good agreement with the simulated results.

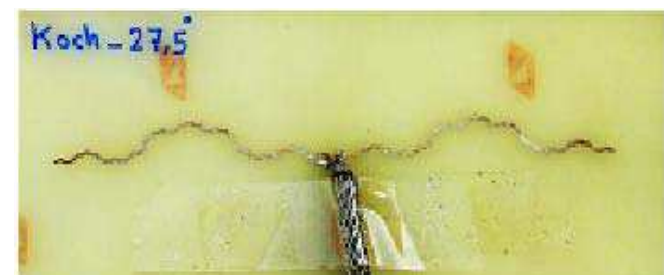

Fig. 17. Photograph of the fabricated K3-27.5 antenna.

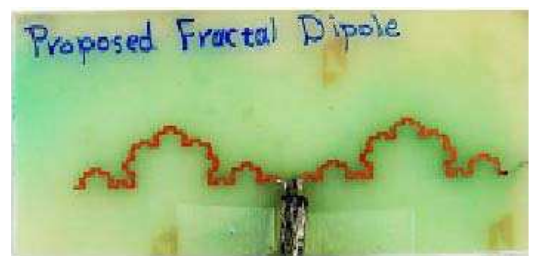

Fig. 18. Photograph of the fabricated (P3) antenna

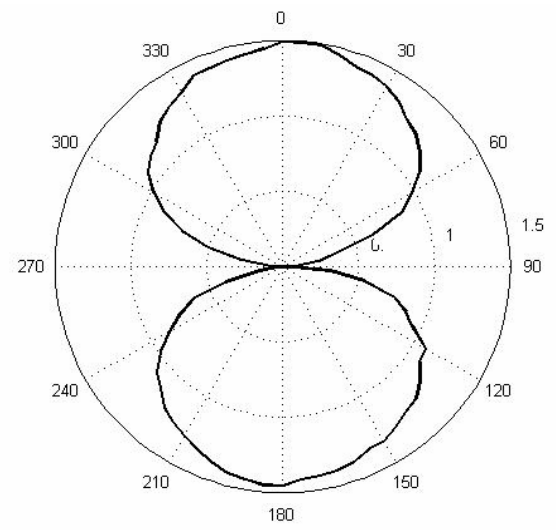

(a)

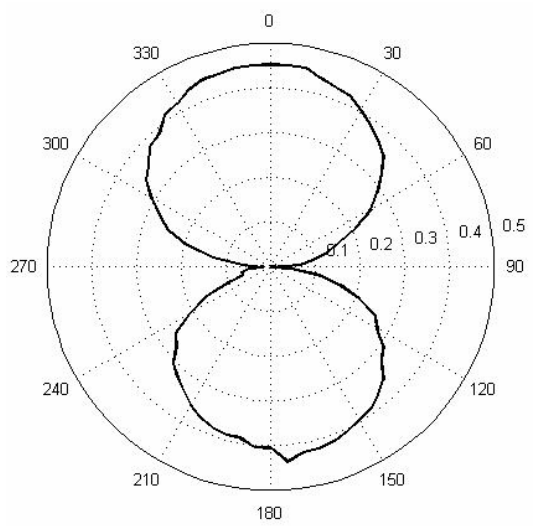

(b)

Fig. 19. Measured radiation pattern of (a) (K3-27.5) antenna and (b) (P3) antenna

\subsubsection{Fractal loop antennas}

In this section, the design and performance of Two fractal loop antennas designed for passive UHF RFID tags at $900 \mathrm{MHz}$ will be investigated; the first one based on the 2nd iteration of the Koch fractal curve and the other based on the $2^{\text {nd }}$ iteration of the new proposed fractal curve with line width (1mm) for both as shown in Fig. 20 (Salama \& Quboa, 2008c). 


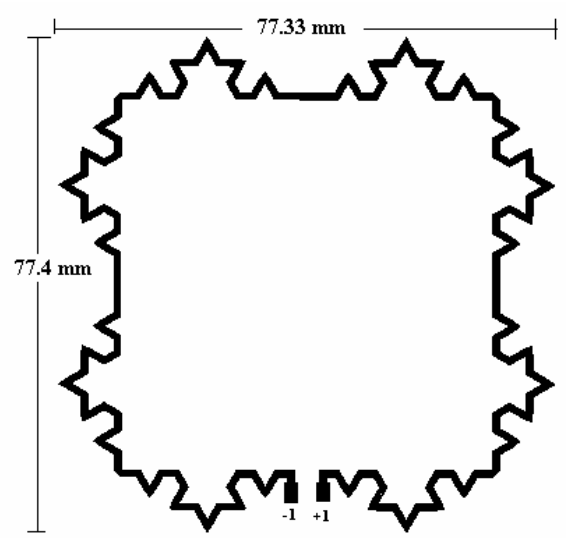

(a)

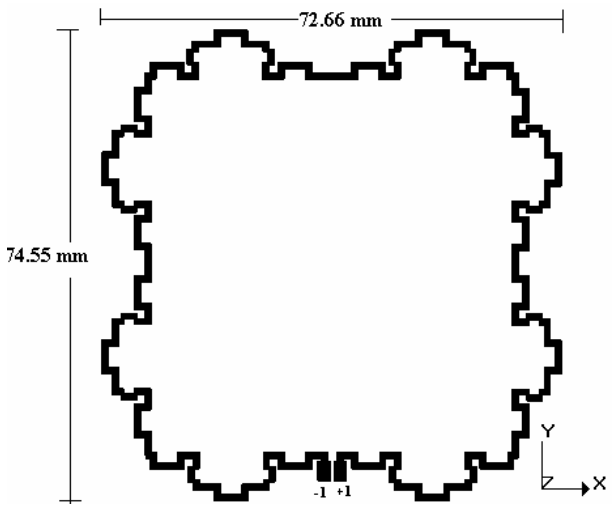

(b)

Fig. 20. The designed fractal loops: (a) Standard Koch fractal loop, (b) The new proposed fractal loop

A loop antenna responds mostly to the time varying magnetic flux density $\vec{B}$ of the incident EM wave. The induced voltage across the 2- terminal's loop is proportional to time change of the magnetic flux $\Phi$ through the loop, which in turns proportional to the area $S$ enclosed by the antenna. In simple form it can be expressed as (Andrenko, 2005):

$$
V \propto \frac{\partial \Phi}{\partial t} \propto \omega|\vec{B}| S
$$

The induced voltage can be increased by increasing the area (S) enclosed by the loop, and thus the read range of the tag will be increased. The proposed fractal curve has a greater area under curve than the standard Koch curve in second iteration. Starting with an initiator of length $(l)$, the second iterations area is $\left(0.0766 \mathrm{l}^{2} \mathrm{~cm}^{2}\right)$ for the proposed curve and $\left(0.0688 \mathrm{l}^{2}\right.$ $\mathrm{cm}^{2}$ ) for the standard Koch curve. According to equation (12) one can except to obtain a significant level of gain from proposed fractal loop higher than that from Koch fractal loop. 
Fig.21 shows the return loss (RL) of the designed loop antennas of $50 \Omega$ balanced feed port, and Table 1 summarizes the simulated results of the designed loop antennas.

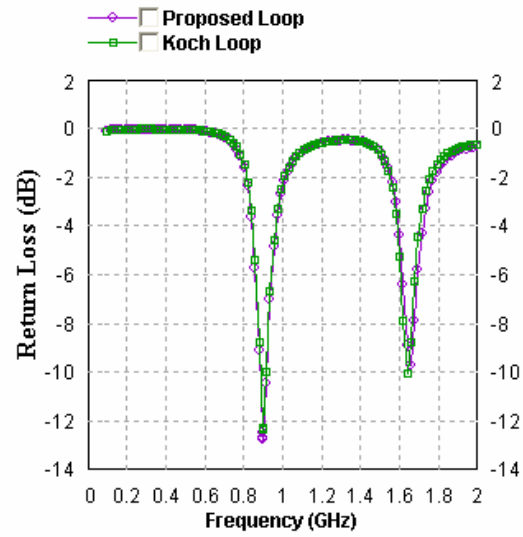

Fig. 21. Return loss of the two loop antennas.

\begin{tabular}{|c|c|c|c|c|c|c|}
\hline Antenna type & $\begin{array}{c}\text { Return } \\
\text { Loss } \\
(\mathbf{d B})\end{array}$ & $\begin{array}{c}\text { BW } \\
\mathbf{( M H z )}\end{array}$ & $\begin{array}{c}\text { Impedance } \\
(\mathbf{\Omega})\end{array}$ & $\begin{array}{c}\text { eff. } \\
\mathbf{( \% )}\end{array}$ & $\begin{array}{c}\text { Gain } \\
\mathbf{( d B i})\end{array}$ & $\begin{array}{c}\text { Read } \\
\text { Range } \\
(\mathbf{m})\end{array}$ \\
\hline Standard Koch Loop & -12.35 & 31.4 & $80.73-j 7.3$ & 78.5 & 1.74 & 6.287 \\
\hline Proposed Loop & -12.75 & 36 & $78.2-\mathrm{j} 8.9$ & 81.8 & 1.97 & 6.477 \\
\hline
\end{tabular}

Table 5. Simulated results of the designed loop antennas.

From Table 1 it can be seen that the proposed fractal loop has better radiation characteristics than the standard Koch fractal loop. As a result, higher read range is obtained. The proposed fractal loop also is smaller in size than the standard Koch fractal loop. The measured radiation pattern is in good agreement with the simulated one for the proposed fractal loop antenna as shown in Fig. 22.

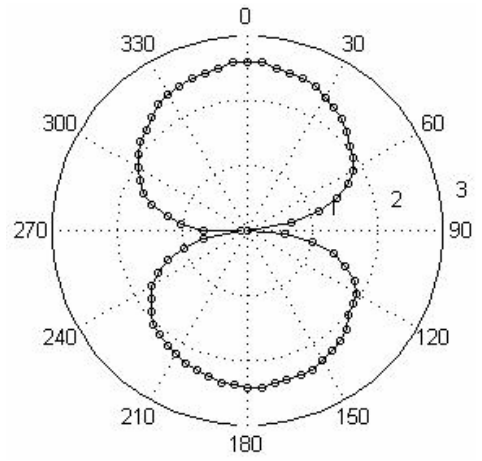

(a)

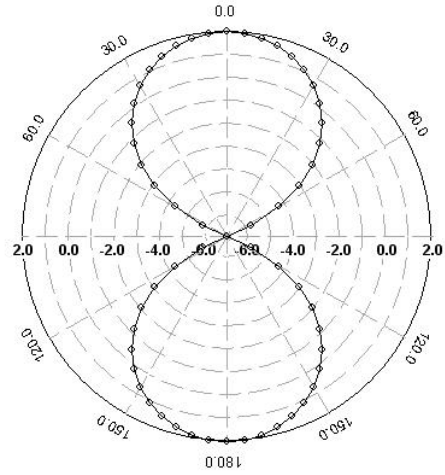

(b)

Fig. 22. The radiation pattern of the proposed fractal loop antenna (Salama et al., 2008).

(a) measured. (b) simulated 
The fabricated proposed fractal loop antenna is shown in Fig.23 below:

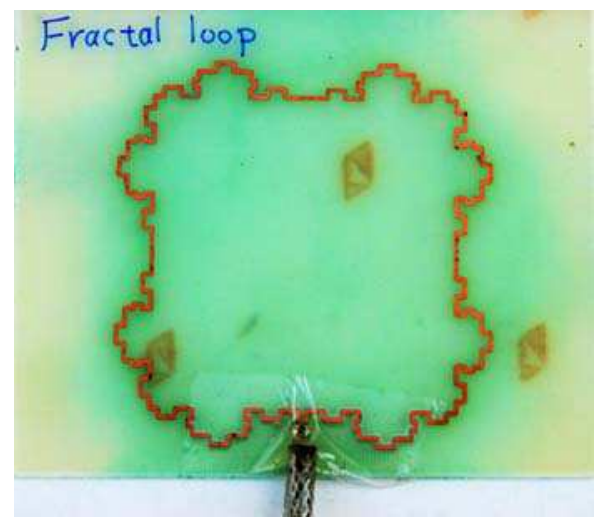

Fig. 23. The fabricated proposed fractal loop antenna.

\subsection{Inverted-F antennas}

A lot of different tag designs have been developed, but one of the biggest challenges nowadays is tagging objects that consist of metal or other conductive material. Printed dipole antennas may be used in RFID tags, but their performance is highly platform dependent. Conversely, microstrip patch antennas are more tolerant to the effects of the platform, but are very large in size. Metal strongly affects the performance of antennas for example by lowering the antenna's radiation efficiency. Metalized objects, such as aluminum cans, are common in most applications that utilize passive RFID systems. Therefore, tag antennas must be designed to enable passive tags to be read near and on metallic objects without performance degradation. Inverted-F antennas is a good solution which is a modification of a quarter-wave monopole antenna. The height of the antenna can be reduced by positioning the radiating element so as parallel with the ground plane while maintaining the resonant length. In Fig. 24 the basic structures of IFA are presented. The microchip is attached to the feed point between the ground plane and the radiating element (Ukkonen et al., 2004a).

Inverted-F antennas can take various shapes and designs according to application and specifications. These types like: planar inverted-F antenna as shown in Fig.25 (Hirvonen et al., 2004) and wire-type inverted-F antenna as shown in Fig.26 (Ukkonen et al., 2004b).

\section{Environmental effects and performance limitations}

RFID tag performance can be affected by many factors. In particular, the electrical properties of objects near or in contact with the tag antenna will be changed. A tag is usually attached directly to the object to be identified. Many common materials, including metals and liquids, have strong effects on the performance of UHF tag antenna (Dobkin \& Weigand, 2005). The effect of different materials has been studied where the RFID tags can be placed in free space (air), on cardboard, directly to metal, on plastic container filled with water and on wood ....etc. Figs. 26, 27 and 28 show the effect of some materials on the return loss of some practical antennas which are mentioned before in this chapter. 

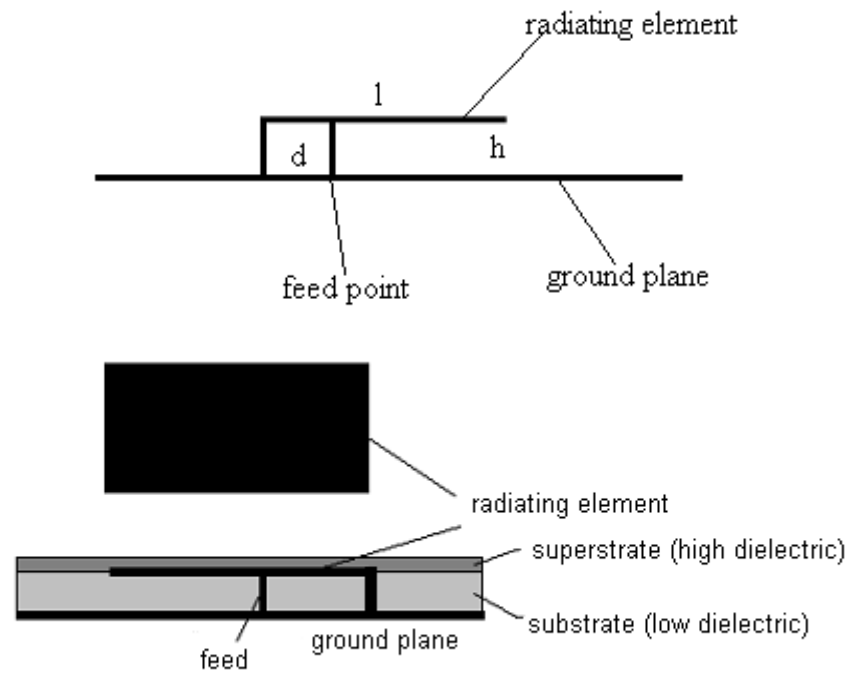

Fig. 24. The Basic structure of IFA.

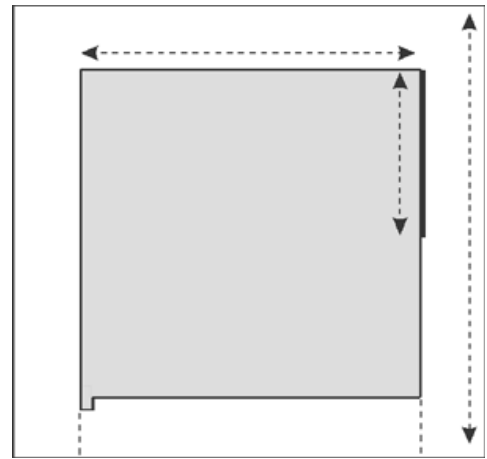

Fig. 24. Planar Inverted-F Antenna.

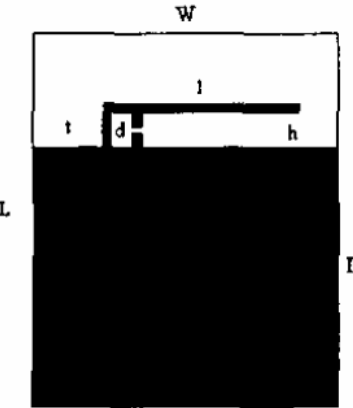

12

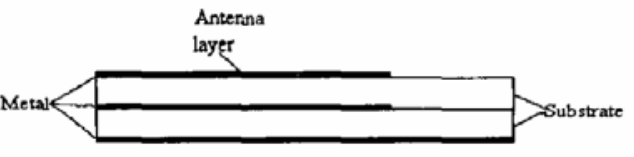

Fig. 25. Wire-type Inverted-F Antenna. 


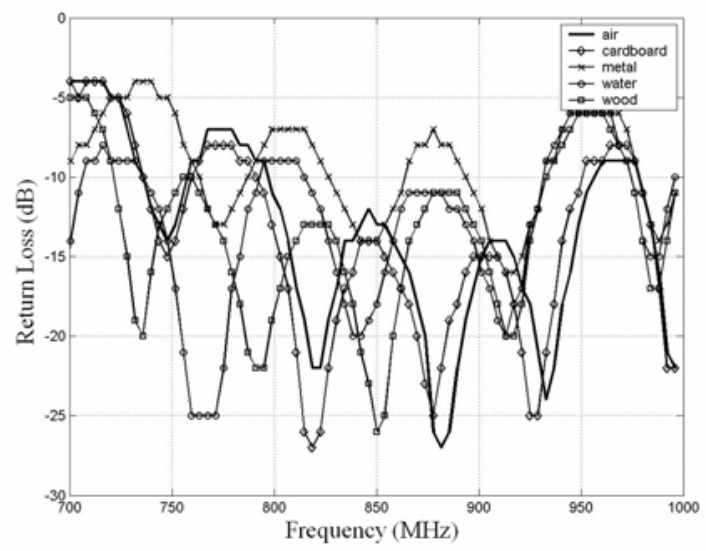

Fig. 26. Effect of different materials on Return loss of the Text Antenna.

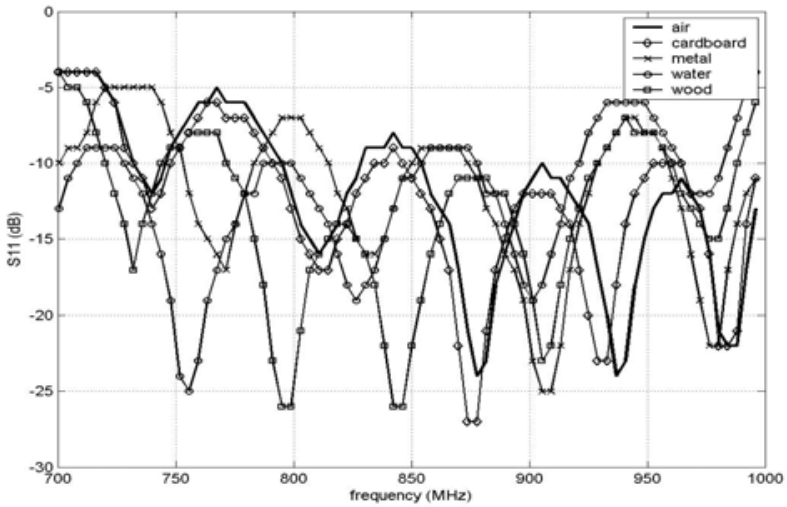

Fig. 27. Effect of different materials on Return loss of the Proposed Fractal Dipole antenna (P3).

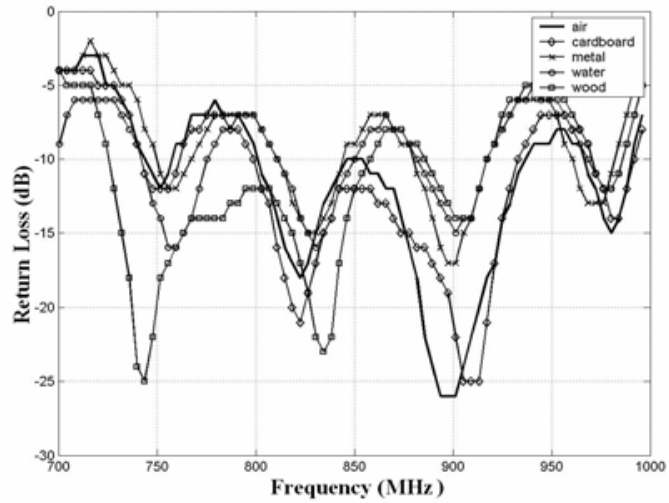

Fig. 28. Effect of different materials on Return loss of the Proposed Fractal Loop Antenna. 
The results showed that the performance of the fractal loop antenna is practically accepted even if the antenna is attached to different materials and has better return loss with attaching materials when compared with other types.

\section{References}

Andrenko A. S., (2005). Conformal Fractal Loop Antennas for RFID Tag Applications, Proceedings of the IEEE International Conference on Applied Electromagnetics and Communications, ICECom., Pages:1-6, Oct. 2008.

Baliarda, C. P.; Romeu J., \& Cardama A., M. (2000), The Koch monopole: A small fractal antenna. IEEE Trans. on Antennas and Propagation, Vol.48, (2000) page numbers (1773-1781).

Curty J. P., Declerdq M., Dehollain C. \& Joehl N., (2007). Design and Optimization Of Passive UHF RFID Systems, Springer, ISBN: 0-387-35274-0, New Jersey.

Dobkin D. M., Weigand S. M., (2005). Environmental Effects on RFID Tag Antennas, Proceedings of IEEE Microwave Symposium Digest, June 2005.

Hirvonen M., Pursula P., Jaakkola K., Laukkanen K., (2003). Planar Inverted-F Antenna For Radio Frequency Identification. Electronics Letters, Vol. 40, No. 14, (July 2004),

Hunt V., Puglia A. \& Puglia M., (2007). RFID A Guide To Radio Frequency Identification, John Wiley \& Sons Inc., ISBN: 978-0-470-10764-5 ,New Jersey.

Nikitin P. V., Rao K. V. S.,(2006). Performance Limitations of Passive UHF RFID Systems, Proceedings of IEEE Antennas and propagation Symposium, pp. 1011-1014, July 2006.

Rao K. V. S. , Nikitin P. V. \& Lam S. F., (2005). Antenna Design For UHF RFID tags: A review and a practical application, IEEE Trans. On Antennas and Propagation., Vol.53, No.12, Dec. 2005, pp. 3870-3876.

Salama A. M. A., Quboa K., (2008a). Text Antenna for Passive UHF RFID Tags, Proceedings of The $5^{\text {th }}$ Congress of Scientific Research Outlook in the Arab World (Scientific Innovation and sustained Development), Morocco, Oct. 2008, Fez.

Salama A. M. A., Quboa K., (2008b). Fractal Dipoles As Meander Lines Antennas For Passive UHF RFID Tags, Proceedings of The IEEE Fifth International Multi-Conference on Systems, Signals and Devices (IEEE SSD'08), Page: 128, Jordan, July 2008.

Salama A. M. A., Quboa K., (2008c). A New Fractal Loop Antenna for Passive UHF RFID Tags Applications, Proceedings of the $3^{\text {rd }}$ IEEE International Conference on Information $\mathcal{E}$ Communication Technologies: from Theory to Applications (ICTTA'08), Page: 477, Syria, April 2008, Damascus.

Ukkonen L., Sydanheimo L. \& Kivikoski M., (2004a). A Novel Tag Design Using Inverted-F Antenna for Radio Frequency Identification of Metallic Objects, Proceedings of IEEE/Sarnoff Symp. On Advances in Wired and Wireless Communication, pp. 91-94, April 2004.

Ukkonen L., Engels D., Sydanheimo L. \& Kivikoski M., (2004b). Planar Wire-type Inverted-F RFID Tag Antenna Mountable On Metallic Objects, Proceedings of IEEE Int. Symp. on AP-S, Vol. 1, pp. 101-104, June 2004.

Werner D. H. \& Ganguly S. (2003). An Overview of Fractal Antenna Engineering Research. IEEE Antennas and Propagation Magazine, Vol.45, No.1, (Feb. 2003), page numbers (38-56).

Zhan J. Q., (2006). RFID Tag Antennas Designed By Fractals and Manufactured By Printing Technologies, Institute of Communication Engineering, Tatung University, June 2006. 


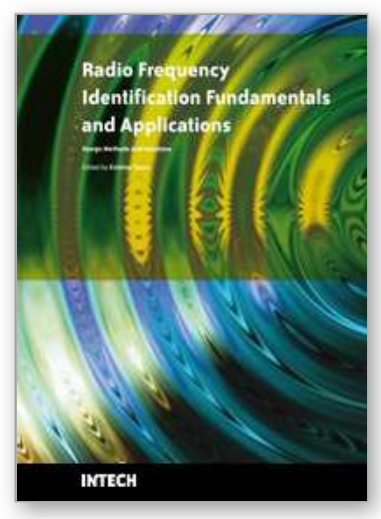

\author{
Radio Frequency Identification Fundamentals and Applications \\ Design Methods and Solutions \\ Edited by Cristina Turcu
}

ISBN 978-953-7619-72-5

Hard cover, 324 pages

Publisher InTech

Published online 01, February, 2010

Published in print edition February, 2010

This book, entitled Radio Frequency Identification Fundamentals and Applications, Bringing Research to Practice, bridges the gap between theory and practice and brings together a variety of research results and practical solutions in the field of RFID. The book is a rich collection of articles written by people from all over the world: teachers, researchers, engineers, and technical people with strong background in the RFID area. Developed as a source of information on RFID technology, the book addresses a wide audience including designers for RFID systems, researchers, students and anyone who would like to learn about this field. At this point I would like to express my thanks to all scientists who were kind enough to contribute to the success of this project by presenting numerous technical studies and research results. However, we couldn't have published this book without the effort of InTech team. I wish to extend my most sincere gratitude to InTech publishing house for continuing to publish new, interesting and valuable books for all of us.

\title{
How to reference
}

In order to correctly reference this scholarly work, feel free to copy and paste the following:

Ahmed M. A. Salama (2010). Antennas of RFID Tags, Radio Frequency Identification Fundamentals and Applications Design Methods and Solutions, Cristina Turcu (Ed.), ISBN: 978-953-7619-72-5, InTech, Available from: http://www.intechopen.com/books/radio-frequency-identification-fundamentals-and-applications-designmethods-and-solutions/antennas-of-rfid-tags

\section{INTECH}

open science | open minds

\author{
InTech Europe \\ University Campus STeP Ri \\ Slavka Krautzeka 83/A \\ 51000 Rijeka, Croatia \\ Phone: +385 (51) 770447 \\ Fax: +385 (51) 686166 \\ www.intechopen.com
}

\author{
InTech China \\ Unit 405, Office Block, Hotel Equatorial Shanghai \\ No.65, Yan An Road (West), Shanghai, 200040, China \\ 中国上海市延安西路65号上海国际贵都大饭店办公楼405单元 \\ Phone: +86-21-62489820 \\ Fax: +86-21-62489821
}


(C) 2010 The Author(s). Licensee IntechOpen. This chapter is distributed under the terms of the Creative Commons Attribution-NonCommercialShareAlike-3.0 License, which permits use, distribution and reproduction for non-commercial purposes, provided the original is properly cited and derivative works building on this content are distributed under the same license. 